\section{Medical malpractice crisis deepens: New approach}

To the Editor: The medical indemnity insurance crisis has entered a new phase with one hospital group informing its doctors that they will be barred from use of its facilities after February 2016 if they do not have an indemnity policy with at least ZAR30 million cover. This attitude is likely to be adopted by the other hospital groups, who are all under pressure to ensure that they are adequately insured for any negligent act that may involve them or their staff jointly with the doctor against whom a claim is being raised. According to one source, the minimum excess that a hospital has to pay per insurable event is ZAR10 million. This requirement will, by some margin, trump the hospital income earned through admissions by an individual practitioner. This means that no individual practitioner can expect leniency from the hospital based solely on their incomegenerating capacity. Add to this new requirement the premium of ZAR650 000 the Medical Protection Society (MPS) has commenced charging its obstetric customers for its occurrence-based cover this year (an increase of ZAR200 000 since 2015), and it becomes easy to appreciate the enormity of the crisis.

Further adding to the obstetricians' woes, and impacting the pocket of their patients, is the continued lack of an appropriate response from the medical scheme industry at large. Many in the industry continue to peg their professional fee maternity benefit at about ZAR3 500, seemingly oblivious of the impact that the rising cost of funding malpractice insurance is having on obstetricians. This is forcing doctors to charge a hefty co-payment for their services in order to meet this burgeoning obligation. A malpractice summit held under the auspices of the Department of Health last year, and the MPS meeting calling for legal reform, have provided some hope for the future, but regulatory change is unlikely to have an impact for several years.

Clark et al. ${ }^{[1,2]}$ in describing their experience in the Hospital Corporation of America (HCA) hospital network, have suggested that another approach is needed. The HCA approach was based on an analysis of 89 closed malpractice claims that indicated that $>80 \%$ of claims against their doctors were the result of substandard care. This led the HCA to restructure their entire approach to labour ward management. Through the application of unambiguous guidelines and protocols in the management of high-risk situations, utilising a team approach involving both doctors and midwives, they were able to reduce the number of claims fourfold and the value fivefold over a period of 10 years. The HCA found that the adoption of their guidelines and protocols was insufficient to bring about the required behaviour change. What was also needed was a way to enforce the adoption of these guidelines. This was made possible in the HCA case through the introduction of a whistle-blower function, whereby even the most lowly member of the obstetric team was encouraged to report any episode of dangerous practice. Mandatory peer review was facilitated by most doctors being employed in HCA hospitals. Independent practitioners who refused to co-operate had their admission privileges withdrawn.

A new approach based on the HCA experience, to be known as the Medical Indemnity Insurance Fund (MIIF), is to be launched in South Africa soon. MIIF will establish a new self-funding insurance scheme by doctors in co-operation with the insurance industry in which agreed guidelines and protocols are adopted and a team approach to obstetrics is established in collaboration with the private hospital networks. Mandatory peer review with leverage provided by fund membership, mediation before litigation, and a policy to defend defendable claims will form a part of the package. The critical success factors will be the establishment and implementation of unambiguous, appropriate guidelines and protocols aimed at reducing episodes of substandard care that compromise patient safety; funding through doctor support; full transparency in relation to costs; spending and financial performance; and the support of experienced insurance market practitioners, insurers and reinsurers.

\section{Chris Archer}

CEO, South African Private Practitioners Forum (SAPPF),

Johannesburg, South Africa

ceo@sappf.co.za

\footnotetext{
1. Clark SL, Belfort MA, Dildy GA, Meyers JA. Reducing obstetric litigation through alterations in practice patterns. Obstet Gynecol 2008;112(6):1279-1283. DOI:10.1097/AOG.0b013e31818da2c7

2. Clark SL, Belfort MA, Byrum SL, Meyers JA, Perlin JB. Improved outcomes, fewer cesarean deliveries, and reduced litigation: Results of a new paradigm in patient safety. Am J Obstet Gynecol
} 2008;199(2):105.e1-e7. DOI:10.1016/j.jpog.2008.02.031

S Afr Med J 2016;106(6):536. DOI:10.7196/SAMJ.2016.v106i6.10407 